\title{
The Basis of Different Sensitivities of Ovarian Cancer Cells to the Recombinant Adenoviral Vector System Containing a Tumor-Specific L-plastin Promoter and E. coli Cytosine Deaminase Gene as a Transcription Unit
}

\author{
Injae CHUNG* \\ College of Pharmacy, Duksung Women's University, Seoul 132-714, Republic of Korea
}

(Received January 28, 2009; Revised March 26, 2009; Accepted April 2, 2009)

\begin{abstract}
We have reported previously on a replication incompetent recombinant adenoviral vector, AdLPCD, in which the expression of cytosine deaminase gene (CD) is driven by the tumor-specific L-plastin promoter. AdLPCD vector had been evaluated for its efficacy of chemosensitization of ovarian cancer cells to 5-FC. In spite of the fact that ovarian cancer cells, i.e., OVCAR-3 and SK-OV-3, are capable for adenoviral transduction judged by LacZ reporter gene analysis, two cell lines demonstrated quite different sensitivities toward AdLPCD/5-FC system. In OVCAR-3 cells, infection of AdLPCD followed by exposure to 5-FC resulted in the suppression of cell growth with statistical significance. On the other hand, SK-OV-3 cells were more resistant to the CD/5-FC strategy compared with OVCAR-3 cells under the same condition. The object of study was to investigate factors that would determine the sensitivity to AdLPCD/5-FC. We evaluated conversion rate of $5-\mathrm{FC}$ to $5-\mathrm{FU}$ after infection of AdLPCD by HPLC analysis, IC $\mathrm{C}_{50}$ of 5 -FU, the expression level of integrin receptors i.e., $\alpha v \beta 3$ and $\alpha v \beta 5$, and status of $p 53$ in OVCAR-3 and SK-OV-3 cells. The results indicated that OVCAR-3 cells have few favorable features compared with SK-OV-3 cells to be more effective to the AdLPCD/5-FC strategy; higher level of $\alpha \vee \beta 5$ integrin, higher rate of conversion of 5-FC into 5-FC, and lower $\mathrm{IC}_{50}$ of 5 -FU. The results suggest that the replacement of 5 - $\mathrm{FU}$ with $\mathrm{CD} / 5-\mathrm{FC}$ in combination chemotherapy would be less toxic and much greater cytotoxicity than the conventional combination chemotherapy in some patients.
\end{abstract}

Keywords: L-plastin promoter, Tumor-specific promoter, Adenoviral vector, Gene therapy, Ovarian cancer, Cytosine deaminase

\section{INTRODUCTION}

Ovarian cancer, when it is found to be recurrent following initial surgical resection and subsequent conventional dose salvage chemotherapy, is predictive of an $80 \%$ mortality rate. Therefore, new chemotherapy drugs or combinations of chemotherapy with other modalities are needed to prolong the survival of patients with advanced stages of ovarian cancer. There have been many attempts to combine recombinant biologicals with chemotherapy (Chung, 2003).

${ }^{1} 5$-Fluorouracil (5-FU) has been the one the major che-

${ }^{*}$ Corresponding author

Tel: +82-2-901-8381 Fax: +82-2-901-8386

E-mail: ijchung@duksung.ac.kr motherapeutic agent in the adjuvant therapy of ovarian carcinoma. The main mechanisms of action of 5-FU include inhibition of thymidylate synthase resulting in a rise of DNA damage, and incorporation into DNA as a false nucleotide. However, additional way to cause cell growth inhibition could be achieved if the intracellular concentrations of 5-FU are sufficiently high and the conversion of 5 -FU into phosphorylated 5-FU is sufficiently fast, which is cell cycle independent cell death by incorporation of the 5-FU into RNA (Kufe and Major, 1981; Grazer and Lloyd, 1982; Pritchard et al., 1997). The E. coli cytosine deaminase (CD) gene (Anderson et al., 1989; Moolten, 1994) converts the harmless drug, 5-fluorocytosine (5-FC), into the cytotoxic agent, 5-FU (Austin and Huber, 1993; Huber et al., 1993). It has been reported that the levels of 5-FU 
which are generated by the CD/5-FC system within tumor cells is much higher than those possible when 5-FU is systemically administered (e.g., Garcia-Sanchez et al., 1998).

Previous studies suggested that the higher concentration of 5-FU could be obtained by the use of the adenoviral vector (AV) carrying the $C D$ gene/5-fluorocytosine (5-FC) system on various tumor cell lines in vivo models (Hirschowitz et al., 1995; Kievit et al., 2000). However, the infectivity of normal as well as tumor cells by the AVs has represented a disadvantage for AVs, since the expression of the therapeutic transgenes in the normal cells generates toxic side effects.

We have shown that it is possible to use of L-plastin (LP) promoter for the regulated expression of an adenoviral exogenous gene in a tumor cell specific manner and spare the normal cells of the body, resulting in the increase of therapeutic index (Chung et al., 1999; Peng et al., 2001; Zhang et al., 2002; Akbulut et al., 2003; Chung and Deisseroth, 2004). Among LP promoter containing recombinant AVs, AdLPCD/5-FC system (Chung and Deisseroth, 2004) has been tested in ovary, breast and colon carcinoma so far and shown effective chemosensitization with different extents (Peng et al., 2001; Zhang et al., 2002; Akbulut et al., 2003). The AdLPCD vector contains the expression cassette consisting of $2.3 \mathrm{~kb}$ of the human LP promoter (Chung et al., 1999) and the E. coli CD gene in E1 region.

In spite of the fact that ovarian cancer cell lines, i.e., OVCAR-3 and SK-OV-3, are capable for adenoviral transduction judged by LacZ reporter gene analysis, two cell lines demonstrated quite different sensitivities toward ADLPCD/5-FC system. Consistent with the knowledge that infection of OVCAR-3 cells with AdLPCD resulted in expression of a functional intracellular $C D$ enzyme capable of converting 5-FC to 5-FU (Chung and Deisseroth, 2004), statistically significant differences in cytotoxicity were observed when AdLPCD infected cells were also exposed to 5-FC compared to 5-FC exposure alone. These results indicate that the $C D$ gene delivered by AV could efficiently sensitize OVCAR-3, otherwise non-toxic 5-FC. On the other hand, SK-OV-3 cells, an ovarian carcinoma cell line, were more resistant to the $\mathrm{CD} / 5-\mathrm{FC}$ strategy compared with OVCAR-3 cells under the same condition (Chung, 2005).

A similar result, that is inefficient chemosensitization by AdLPCD/5-FC system in human hepatocellular carcinoma HepG2 cells, was observed. HepG2 cells also exhibited LacZ expression by the infection of AdLPLacZ viral vector and contains endogenous L-plastin transcript (Jung et al., 2007). These data suggest that the screening of potential patient based on the results of AdLPLacZ could result in the failure of therapeutic outcome.

At least, the higher transduction efficiency of AdLPLacZ vector to OVCAR-3 cells than SK-OV-3 cells was observed in previous study, comparing the expression of LacZ gene in $30-95 \%$ of OVCAR-3 cells versus $20-70 \%$ of SK-OV-3 cells measured by FACS-galactosidase (Chung et al., 1999).

These observations had led us to investigate the basis causing the different sensitivity toward the AdLPCD/5-FC treatment in ovarian cancer cells. We evaluated the conversion rate of 5-FC to 5-FU in the cells after infection of AdLPCD vector by HPLC analysis, the $\mathrm{IC}_{50}$ of $5-\mathrm{FU}$, the level of expression of integrin receptors such as $\alpha \mathrm{v} \beta 3$ and $\alpha v \beta 5$, and status of p53 in OVCAR-3 and SK-OV-3 cells.

\section{MATERIALS AND METHODS}

\section{Production and purification of AdLPCD}

AdLPCD is an E1a-, partial E1b-, partial E3-, linear double stranded adenovirus vector based on the Ad5 genome. AdLPCD vector contains the expression cassette consisted of the $2.3 \mathrm{~kb}$ of human L-plastin promoter and the $E$. coli cytosine deaminase (CD) gene in E1 region (Chung and Deisseroth, 2004).

The replication-incompetent adenoviral vectors were propagated in 293 cells and recovered $36 \mathrm{hr}$ after infection by five cycles of freezing/thawing the infected cells. All viral preparations were purified by Cycle density centrifugation, dialyzed, and stored in dialysis buffer $(10 \mathrm{mM}$ Tris- $\mathrm{HCl}, \mathrm{pH}$ $7.4,1 \mathrm{mM} \mathrm{MgCl} 2$ ) at $-70^{\circ} \mathrm{C}$ prior to use. Titers of the viral stocks were determined by plaque assay using 293 cells by standard methods (Graham and Prevec, 1991). The titers of vector were in the range between $2 \times 10^{10}$ and $1 \times 10^{11}$ $\mathrm{pfu} / \mathrm{ml}$. The organization of the L-plastin cytosine deaminase adenoviral vector is shown in Fig. 1.

\section{Cell culture}

The cells were maintained in IMEM (Biofluids, Rockville, MD) supplemented with $10 \%$ fetal bovine serum (FBS) and $2 \mathrm{mM}$ glutamine (in the case of the 293 cell line), in DEME/F12 (GIBCO BRL) supplemented with 10\% FBS (in the case of OVCAR-3 and SK-OV-3).

\section{HPLC analysis for cytosine deaminase activity from AdLPCD infected cells}

A day after plating cells on $6 \mathrm{~cm}^{2}$ dish, the cells were infected with AdLPCD vector at 10, 100 and $200 \mathrm{MOI}$ (multiplicity of infection) for $90 \mathrm{~min}$ followed by the treatment of $100 \mathrm{M}$ of $5-\mathrm{FC}$ and $10 \mathrm{Ci}$ of $\left[6-{ }^{3} \mathrm{H}\right]-5-\mathrm{FC}$. Cells were further 


\section{AdLPCD}

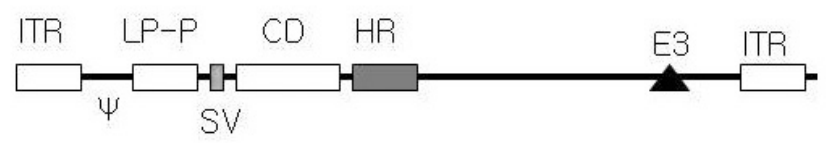

\section{AdLPLacZ}

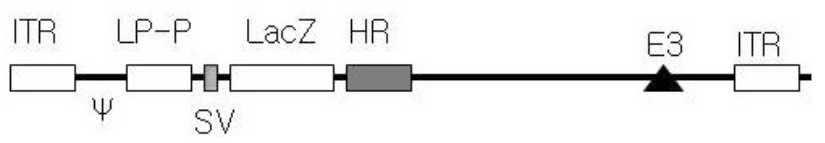

Fig. 1. The map of replication-incompetent adenoviral vectors mentioned in the study. In the AdLPCD vector, the CD gene is driven by the $2.4 \mathrm{~kb}$ of L-plastin promoter. AdLPLacZ vector contains $E$. coli -galactosidase gene under the control of L-plastin promoter. ITR: adenoviral inverted terminal repeat, $\psi$ : packaging signal, LP-P: L-plastin promoter: SV: SV40 splice donor/acceptor site, HR: homologous in sequence to those present in the pBHG10 adenoviral vector plasmid, E3: early transcription unit 3.

incubated for $24 \mathrm{hr}$ in a $5 \mathrm{ml}$ of medium which contained $150 \mathrm{mM} 5-\mathrm{FC}$ and $20 \mu \mathrm{l}$ of $\left[6-{ }^{3} \mathrm{H}\right]-5 \mathrm{FC}$ (specific activity: 20 $\mathrm{Ci} / \mathrm{mmol}$, Moravek Biochemicals, Brea, CA). After dilution of an aliquot of the medium at 1:10, the conversion of 5-FC to 5-FU was evaluated by HPLC (high performance liquid chromatography) on a Microsorb C18 reverse phase column, $25 \mathrm{~cm} \times 4.6 \mathrm{~mm}$ i.d. (Rainin, Inc., Woburn, MA), eluted with $50 \mathrm{mM}$ potassium phosphate monobasic $\left(\mathrm{KH}_{2} \mathrm{PO}_{4}\right)$, $\mathrm{pH} 3.0$ at room temperature. The retention times for 5 -FC and 5-FU were about $6.10 \mathrm{~min}$ and $8.70 \mathrm{~min}$, respectively. Fractions were collected at 1 minute interval followed by counting radioactivity after addition of scintillation fluid.

\section{Integrin analysis}

Monoclonal antibodies used to detect the human $\alpha v \beta 3$ (LM609) and $\alpha \mathrm{v} \beta 5$ (P1F6) were purchased from Chemicon International (Tamecula, CA). SK-OV-3 and OVCAR-3 cells were stained with each monoclonal antibody using standard procedures. Flow cytometry was performed using a FACStar flow cytometer (Becton Dickinson). The percentage of tumor cells positive for $\alpha v \beta 3$ and $\alpha v \beta 5$ receptors and their densities on cell surfaces, which had been indicated as geometry mean, were measured.

\section{Immunoprecipitation analysis}

Radiolabeled protein mixture was prepared as follows. The cells were cultured with media containing with ${ }^{35} \mathrm{~S}$-methionine for $3 \mathrm{hr}$. The harvested cells were lysed with 500 $\mu$ l of lysis buffer and subjected to the centrifugation. $5 \mu \mathrm{g}$ of mouse Ig and $65 \mu$ l of protein A/S plus agarose were added in supernatant. After centrifugation, the supernatants were incubated with $1 \mu \mathrm{g}$ of p53 monoclonal antibody, i.e., Ab-5 (Oncogene science) and $65 \mu \mathrm{l}$ of protein A/S plus agarose. After washing, the radiolabled proteins were analyzed by SDS-PAGE separation followed by autoradiography.

\section{Chemosensitization assays}

Cells were plated in triplicate monolayer a day before the treatments. $\mathrm{IC}_{50}$ (half maximal inhibitory concentration) was determined at 6 days after initial addition of various concentration of 5 -FU. The viable cell number was assessed using 3-[4, 5-dimethylthiazol-2-yl]-2, 5-diphenyltetrazolium bromide (MTT).

\section{Statistical analysis}

Significance levels for comparison between treatment groups were determined using the two-sided Student's $t$ test for paired samples.

\section{RESULTS}

\section{Conversion of 5-FC to 5-FU in OVCAR-3 and SK-OV-3 cells after infection of AdLPCD}

To compare the conversion rate of $5-\mathrm{FC}$ to $5 \mathrm{FU}$ in OVCAR-3 and SK-OV -3 cell lines, cells were infected with AdLPCD vector at $\mathrm{MOI}$ of 10,100 , and 250 for $90 \mathrm{~min}$ followed by the treatment of $100 \mu \mathrm{M}$ of $5-\mathrm{FC}$ and $10 \mu \mathrm{Ci}$ of [6- $\left.{ }^{3} \mathrm{H}\right]-5-\mathrm{FC}$. At $48 \mathrm{hr}$ after infection, an aliquot of media were subjected to HPLC analysis followed by counting the fractions in scintillation counter for radioactivity (Table I). Dose-dependent increase in conversion rate was observed in both cell lines. At MOI of 10, extremely low level $(1.25 \%)$ of conversion occurred in SK-OV-3 cells, whereas nearly $30 \%$ of $5-\mathrm{FC}$ were converted to 5 -FU in OVCAR-3 cells resulting almost 28 times difference between two cell lines. The conversion rate reached to maximum of $55 \%$ with $\mathrm{MOI}$ of 100 and no further increment were observed when infected with higher MOI of 250 in OVCAR-3 cells. In contrast, SK-OV-3 cells showed a continued increment in conversion rate.

These results indicated that OVCAR-3 cells could convert a prodrug, 5-FC, to active compound, 5-FU, more efficiently than SK-OV-3 cells.

\section{Comparison of the 5-FU sensitivity of cell lines deter- mined as $\mathrm{IC}_{50}$}

It is possible that the lower level of sensitivity of 
Table I. Conversion rate of 5-FC to 5-FU

\begin{tabular}{ccc}
\hline Treatment & OVCAR-3 & SKOV-3 \\
\hline 10 MOI AdLPCD & $30.5 \%$ & $0.7 \%$ \\
100 MOI AdLPCD & $54.1 \%$ & $11.6 \%$ \\
250 MOI AdLPCD & $55.0 \%$ & $22.6 \%$ \\
\hline
\end{tabular}

Cells were infected with AdLPCD vector at MOI of 10,100, and 250 for $90 \mathrm{~min}$ followed by the treatment of $100 \mathrm{M}$ of $5-\mathrm{FC}$ and $10 \mathrm{Ci}$ of $\left[6-{ }^{3} \mathrm{H}\right]-5-\mathrm{FC}$. At $48 \mathrm{hr}$ after infection, an aliquot of media were subjected to HPLC analysis followed by counting the fractions in scintillation counter for radioactivity.

Table II. IC I0 $_{50}$ of-FU in OVCAR-3 and SK-OV-3 cell lines

\begin{tabular}{lc}
\hline Cell line & $\mathrm{IC}_{50}(\mu \mathrm{M})$ of 5-FU \\
\hline OVCAR-3 & $1-2.5$ \\
SKOV-3 & $5-10$ \\
\hline
\end{tabular}

$\mathrm{IC}_{50}$ was determined by MTT test at 6 days after initial addition of various concentrations of 5-FU.

SK-OV-3 cells than OVCAR-3 cells could be attributable to intrinsic resistance to 5 -FU. To test this, the intrinsic sensitivity of each cell lines to 5 -FU was evaluated by measuring $\mathrm{IC}_{50}$ of 5-FU. To determine the $\mathrm{IC}_{50}$ of 5-FU in both cell lines, various concentrations of 5-FU were included in cell culture. Inhibition of cell growth by 5-FU was determined by MTT test at 6 days after initial 5 -FU treatment. $50 \%$ of cells were remained when OVCAR- 3 and SK-OV- 3 cells were incubated with 5-FU at the concentration of $1-2.5 \mu \mathrm{M}$ and 5-10 $\mu \mathrm{M}$, respectively (Table II). These observations suggested that OVCAR- 3 cells are more sensitive to 5-FU treatment than SK-OV-3 cells.

\section{Evaluation of the levels of avb3 and avb5 integrin expre- ssion}

Since the presence of $\alpha v \beta 3$ and $\alpha v \beta 5$ integrins, which bind to the adenovirus penton base and partly, mediate adenovirus internalization (Wickham et al., 1993, 1994; Goldman and Wilson, 1995), the level of these integrins on the surface of OVCAR-3 and SK-OV-3 cells were compared (Table III). $82.5 \%$ and $87 \%$ of OVCAR-3 cells expressed the $\alpha \vee \beta 3$ and $\alpha \vee \beta 5$ integrin, respectively, whereas $93.8 \%$ and $88.1 \%$ of SK-OV-3 cells were positive for the expression of $\alpha \vee \beta 3$ and $\alpha \vee \beta 5$ integrin, respectively. There was no significant difference in the expression of these integrins between two cell lines when compared for the positivity of cells. However, there was a meaningful difference in av 35 integrin expression when two cells were compared for density of integrin on their cell surface, which was described as geometry mean. OVCAR-3 cells contain 2.5 times more $\alpha v \beta 5$ integrin than SK-OV- 3 cells.
Table III. Comparisons of levels of integrins in OVCAR-3 and SK-OV-3 cell lines

\begin{tabular}{|c|c|c|c|c|}
\hline \multirow{3}{*}{ Cell line } & \multicolumn{4}{|c|}{ Expression of Integrins } \\
\hline & \multicolumn{2}{|c|}{ Positive cells (\%) } & \multicolumn{2}{|c|}{ Geometry Mean } \\
\hline & $\alpha v \beta 3$ & $\alpha v \beta 5$ & $\alpha v \beta 3$ & $\alpha v \beta 5$ \\
\hline OVCAR-3 & 82.5 & 87.0 & 25.3 & 18.5 \\
\hline SK-OV-3 & 93.8 & 88.1 & 27.5 & 7.5 \\
\hline
\end{tabular}

The percentage of tumor cells positive for av $\beta 3$ and av $\beta 5$ receptors and their densities on cell surfaces (indicated as geometry mean) were measured by the fluorescence-activated cell sorter analysis.

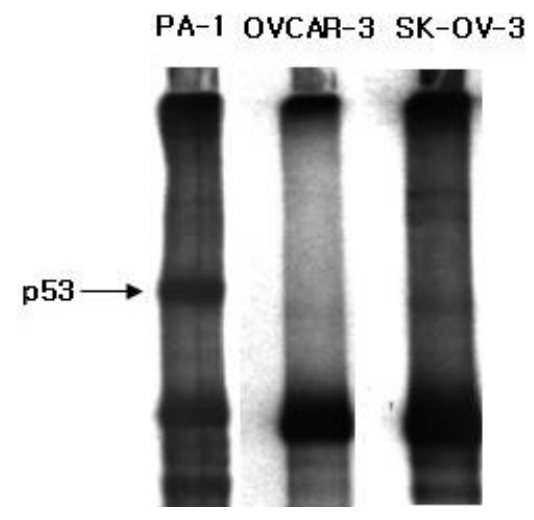

Fig. 2. Comparisons of ovarian carcinoma cell lines for the expression of wild-type p53. Immunoprecipitation assay was conducted to detect the p53 expression by using antibody Ab-5 (Oncogene Science), which binds to wild type of p53 protein.

\section{The status of p53 in both cell lines}

The level of intrinsic sensitivity of tumor to active compound would be a factor, which determines an outcome of enzyme-prod rug activation strategy. Among the molecules, which have been searched for relating to 5-FU sensitivity, the status of p53 was found to be the case in many cancer cell types (Pritchard et al., 1997; Higashiyama et al., 1998; Lenz et al., 1998).

As shown in Fig. 2, in regard to the p53 expression, there was no detectable wild type p53 expression in OVCAR-3 and SK-OV-3 cells as determined by immunoprecipitation assay using Ab-5 antibody which recognizes the wild type of p53. Ab-5, on the other hand, was able to immunoprecipitate the p53 present in PA-1 cells, another ovarian carcinoma cells, under the same condition.

These results indicated that OCVAR- 3 cells have at least a few favorable features compared with SK-OV-3 cells to be more effective to the AdLPCD/5-FC strategy, which include higher level of $\alpha v \beta 5$ integrin, higher rate of conversion of 5-FC to $5-\mathrm{FU}$, and lower $\mathrm{IC}_{50}$ of 5-FU. 


\section{DISCUSSION}

We previously developed an AV containing a transcription unit in which transgene expression is under the control of $2.4 \mathrm{~kb}$ of human LP promoter. The pattern of $\beta$-galactosidase expression was tumor-specific in various cell lines when LacZ gene had been placed at the downstream of LP promoter in an AV. Moreover, the LP promoter drove the expression of $\beta$-galactosidase not in normal mesothelium sample from patient biopsy but in the microscopic ovarian cancer samples which were isolated from patient ascitic fluids. Moreover, the level of promoter activity has a compatible strength of transcriptional activity with the CMV promoter (Chung et al., 1999). The selection of promoter which would direct therapeutic gene to express at the level high enough to be effective and in a selective manner to be safe is an important factor to succeed.

The expression of $E$. coli CD gene delivered by an AV containing LP promoter, in the human ovarian tumor cell line, OVCAR-3, inhibited OVCAR-3 cell growth completely when the cells are growing in culture containing 5-FC. This inhibition was occurred by the heterologously originated CD-mediated conversion of 5-FC to 5-FU and subsequent anabolites in OVCAR-3 cells. To confirm that the increased sensitivity to 5-FC in AdLPCD infected cells was the results of the conversion of 5-FC to 5-FU, cells were cultured in the presence of $\left[6-{ }^{3} \mathrm{H}\right]-\mathrm{FC}$ after infection with the vector. Analysis demonstrated that there was selective conversion of 5-FC to 5-FU in AdLPCD infected cells in a dose-dependent manner (Chung and Deisseroth, 2004)

The efficacy of enzyme-prodrug activation strategy in which heterologous enzyme is delivered by an AV could dependent on various factors occurring in patients. These factors include (1) the efficient transduction of AV to tumor, (2) the level of transgene expression, (3) the level of sensitivity of tumor to active compound, (4) availability of metabolic transformation to final anabolite, and (5) the extent of bystander effects.

Two steps necessary for the transduction of adenoviral vector are proposed and the proteins responsible for these steps are identified. The attachment of fiber proteins of adenovirus to CAR (coxakivirus and adenovirus receptor) on target cells (Bergelson et al., 1997) followed by the internalization of virus, which is mediated by interactions between penton bases of adenovirus and subsets of integrin such as $\alpha v \beta 3$ and $\alpha v \beta 5$ on cell surface (Wickham et al., 1993; Wickahm et al., 1994; Goldman and Wilson, 1995). Comparison of OVCAR-3 and SK-OV-3 cell lines for the differential expression of $\alpha v \beta 3$ and $\alpha v \beta 5$ in this study manifested the higher density of $\alpha v \beta 5$ integrin in OVCAR-3 cells compared with SK-OV-3 cells, which might have indicated more favorable environment for OVCAR-3 for AV infection. However, the extent of CAR receptor expression by which fiber proteins are attached to cells is remained to be evaluated since the percentages of cells expressing two integrins were found to be similar in both cell lines.

The level of intrinsic sensitivity of tumor to active compound would be a factor which determines an outcome of enzyme-prodrug activation strategy. Among the molecules which have been searched for relating to 5-FU sensitivity, the status of p53 was found to be the case in many cancer types (Pritchard et al., 1997; Higashiyama et al., 1998; Lenz et al., 1998). p53 is believed to function as a regulator of a $\mathrm{G} 1$ and $\mathrm{S}$ cell cycle check point and as an inducer of apoptosis following DNA damage to the cell. In present study, OVCAR-3 and SK-OV-3 cells were examined for the status of p53. An antibody for wild-type p53 protein failed to detect the expression of p53 in both cell lines, whereas the same antibody could recognize the p53 in PA-1 cells which is an ovarian cancer cells. According to a report on the status of p53 in ovarian cancer cell lines, while PA-1 cells has a silent mutation, OVCAR-3 and SK-OV-3 cells contain missense mutation (Yaginuma and Westphal, 1992).

The differences in sensitivity of OVCAR-3 and SK-OV-3 cells to CD/5-FC strategy could not be explained by differences in the type or level of p53, since both cell lines express a mutated p53 with a change of one amino acid at a low level.

Since the L-plastin promoter in our previous study was active in ovarian cancer cell line and fresh ascitic ovarian cancer cells, but in active in samples of normal peritoneum, AdLPCD combined with 5-FC administration may have significant utility in the chemosensitization of ovarian cancer carcinoma metasized into intraperitoneal cavity in some patients.

\section{ACKNOWLEDGMENTS}

This study was supported by the Korea Research Foundation Grant (2004).

\section{REFERENCES}

Akbulut, H., Zhang, L., Tang, Y. and Deisseroth, A. (2003). Cytotoxic effect of replication-competent adenoviral vectors carrying L-plastin promoter regulated $\mathrm{E} 1 \mathrm{~A}$ and cytosine deaminase genes in cancers of the breast, ovary and colon. Cancer Gene. Ther. 10, 388-395.

Anderson, L., Kilstrup, M. and Neuhard, J. (1989). Pyrimidine, purine and nitrogen control of cytosine deaminase synthesis 
in Escherichia coli K12. Involvement of the glnG and purR genes in the regulation of codA expression. Arch. Microbiol. 152, 115-118.

Austin, E. A. and Huber, B. E. (1993). A first step in the development of gene therapy for colorectal carcinoma: cloning, sequencing, and expression of $\mathrm{E}$. coli cytosine deaminase. Mol. Pharmacol. 43, 380-387.

Bergelson, J. M., Cunningham, J. A., Droguett, G., Kurt-Jones, E. A., Krithivas, A., Hong, J. S., Horwitz, M. S., Crowell, R. L. and Finberg, R. W. (1997). Isolation of a common receptor for cosackie $B$ viruses and adenoviruses 2 and 5 . Science 275, 1320-1323.

Chung. I. (2003). Cancer gene therapy: history and major developments. J. Toxicol. Pub. Health. 19, 247-257.

Chung, I. (2005). Chemosensitization of human ovarian carcinoma cells by a recombinant adenoviral vector containing L-plastin promoter fused to cytosine deaminase transcription unit. $J$. of Applied Pharmacol. 13, 143-149.

Chung, I. and Deisseroth, A. B. (2004). Recombinant adenoviral vector containing tumor-specific L-plastin promoter fused to cytosine deaminase gene as a transcription unit : Generation and Functional Test. Arch. Pharm. Res. 27, 633-639.

Chung, I., Schwartz, P. E., Crystal, R. G., Pizzorno, G., Leavitt, J. L. and Deisseroth, A. B. (1999). Use of L-plastin promoter to develop an adenoviral system that confers transgene expression in ovarian cancer cells but not in normal mesothelial cells. Cancer Gene. Ther. 6, 99-106.

Garcia-Sanchez, F., Pizzorno, G., Fu, S. Q., Nanakorn, T., Krause, D. S., Liang, J., Adams, E., Leffert, J. J., Yin, L. H., Cooperberg, M. R., Hanania, E., Wang, W. L., Won, J. H., Peng, X. Y., Cote, R., Brown, R., Burtness, B., Giles, R., Crystal, R. and Deisseroth, A. B. (1998). Cytosine deaminase adenoviral vector and 5-fluorocytosine selectively reduce breast cancer cells 1 million-fold when they contaminate hematopoietic cells: a potential purging method for autologous transplantation. Blood 92, 672-682.

Glazer, R. I. and Lloyd, L. S. (1982). Association of cell lethality with incorporation of 5-fluorouracil and 5-fluoridine into nuclear RNA in human colon carcinoma cells in culture. Mol. Pharmacol. 21, 468-473.

Goldman, M. J. and Wilson, J. M. (1995). Expression of avb3 and avb5 integrin is necessary for efficient adenovirusmediated gene transfer in the human airway. J. Virol. 69 , 5951-5958.

Graham, F. L. and Prevec, L. (1991). Manipulation of adenovirus vectors, Methods in molecular biology, Vol. 7, p109128, E. J. Murray, The Human Press Inc., Clifton, NJ.

Higashiyama, M., Kodama, K., Yokouchi, H., Takami, K., Doi, O., Kobayashi, H., Tanisaka, K. and Minamigawa, K. (1998). Immunohistochemical p53 protein status in nonsmall cell lung cancer is a promising indicator in determining in vitro chemosensitivity to some anticancer drugs. J. Surg. Oncol. 68, 19-24.

Hirschowitz, E. A., Ohwada, A., Pascal, W. R., Russi, T. J. and Crystal, R. G. (1995). In vivo adenovirus-mediated gene transfer of the Escherichia coli cytosine deaminase gene to human colon carcinoma-derived tumors induces chemosensitivity to 5-fluorocytosine. Hum. Gene Ther. 6, 10551063.

Huber, B. E., Austin, E. A., Good, S. S., Knick, V. C., Tibbels, S. and Richards, C. A., (1993). In vivo antitumor activity of 5 -fluorocytosine on human colorectal carcinoma cells genetically codified to express cytosine deaminase. Cancer Res. 3, 4619-4626.

Jung, K., Kim, S., Lee, K., Kim, C. and Chung, I. (2007). Cytotoxic effect of a replication-incompetent adenoviral vector with cytosine deaminase gene driven by L-plastin promoter in hepatocellular carcinoma cells. Arch. Pharm. Res. 30, 770-777.

Kievit, E., Nyati, M. K., Ng, E., Stegman, L. D., Parsels, J., Ross, B. D., Rehemtulla, A. and Lawrence, T. S. (2000). Yeast cytosine deaminase improves radiosensitization and bystander effect by 5 -fluorocytosine of human colorectal cancer xenografts. Cancer Res. 60, 6649-6655.

Kufe, D. W. and Major, P. P. (1981). 5-Fluorouracil incorporation into human breast carcinoma RNA correlates with cytotoxicity. J. Biol. Chem. 256, 9802-9805.

Lenz, H. J., Hayashi, K., Salonga, D., Danenberg, K. D., Danenberg, P. V., Metzger, R., Banerjee, D., Bertino, J. R., Groshen, S., Leichman, L. P. and Leichman, C. G. (1998). p53 point mutations and thymidylate synthase messenger RNA levels in disseminated colorectal cancer: an analysis of response and survival. Clin. Cancer Res. 4, 1243-1250.

Moolten, F. L. (1994). Drug sensitivity (suicide) genes for selective cancer chemotherapy. Cancer Gene Ther. 1, 279-287.

Peng, X. Y., Won, J. H., Rutherford, T., Fujii, T., Zelterman, D., Pizzorno, G., Sapi, E., Leavitt, J., Kacinski, B., Crystal, R., Schwartz, P. and Deisseroth, A. (2001). The use of the L-plastin promoter for adenoviral-mediated, tumor-specific gene expression in ovarian and bladder cancer cell lines. Cancer Res. 61, 4405-4413.

Pritchard, D. M., Watson, A. J., Potten, C. S., Jackman, A. L. and Hickman, J. A. (1997). Inhibition by uridine but not thymidine of p53-dependent intestinal apoptosis initiated by 5-fluorouracil: evidence for the involvement of RNA perturbation. Proc. Natl. Acad. Sci. USA. 94, 1795-1799.

Wickham, T. J., Filardo, E. J., Cheresh, D. A. and Nemerow, G. R. (1994). Integrin $\alpha v \beta 5$ selectively promotes adenovirus mediated cell membrane permeabilization. J. Cell Biol. 127, 257-264.

Wickham, T. J., Mathias, P., Cheresh, D. A. and Nemerow, G. (1993). Integrins $\alpha \vee \beta 3$ and $\alpha \vee \beta 5$ promote adenovirus internalization but not virus attachment. Cell 73, 309-319.

Yaginuma, Y. and Westphal, H. (1992) Abnormal structure and expression of the p53 gene in human ovarian carcinoma cell lines. Cancer Res. 52, 4196-4199.

Zhang, L., Akbulut, H., Tang, Y., Peng, X., Pizzorno, G., Sapi E., Manegold, S. and Deisseroth, A. (2002). Adenoviral vectors with $\mathrm{E} 1 \mathrm{~A}$ regulated by tumor-specific promoters are selectively cytolytic for breast cancer and melanoma. Mol. Ther. 6, 386-393. 